\title{
Parent-Teacher-Learner Collaboration in Modular Distance Learning
}

\author{
Elymar A. Pascual \\ elymarpascual@ rocketmail.com \\ Talangan Integrated National High School, Nagcarlan, Laguna, Philippines, 4002
}

\begin{abstract}
In the advent of pandemic due to COVID 19, modular distance learning became the mostly implemented approach in many schools in the Philippines - the school prepares and distributes learning materials, students stay at home and perform learning tasks, while parents assist in supervision. This study dealt with the role of parents, teachers and learners as they collaborate and bring about the best in education amidst pandemic. Fifteen respondents constituting of parents, teachers and learners participated in this qualitative research. Ten questions were solicited through Google forms on a weekly interval as the modular distance learning was being implemented in Talangan Integrated National High School, Nagcarlan, Laguna, Philippines. Qualitative questions pertaining to parents' assistance and supervision, preparation of module and supplemental materials, provision of feedbacks, and learning habits were sent for the respondents to share ideas based on their experiences. Data were encoded, processed through word cloud generator, interpreted, and analyzed thematically in order to construct conclusion about meaningful collaboration amidst pandemic. Themes developed encompassed parents, teachers and learners contribution in collaboration. Parents' hindrances to collaboration can be classified as internal and external in which, both can be mitigated through school intervention. Teachers can motivate parents in the process of collaboration when they reach out, give quality time and show real concern for learners' interest. Learners are advised to avoid cramming, procrastinating, distractions, and set goals for themselves associated with every modular lesson. Recommendations were laid down to school heads and community partners, institutionalizing modular distance learning if pandemic still prevails.
\end{abstract}

Keywords: Modular; Parent; Teacher

\section{Introduction}

The onset of the COVID 19 Pandemic in the first quarter of this year 2020 somehow perplexed educators on how to possibly deliver quality education to the youth. Teacher around the world have explored different approaches as a solution to a non-face-to-face interaction that the pandemic calls for. Several researches have been designed so as to share experience in teaching under the new normal, and thereby make the readers ready on how they would possibly deal with education in their own locality. There is the insertion of different online activities to learners so as to sustain their interest while in virtual meeting. Kids were made to express what they feel, not only in social media, but also virtual meeting apps because it is believed that if they would not be allowed to do so, the spiral of silence would promulgate, thereby causing social media anxiety.

The Department of Education in the Philippines has three learning modalities as a solution to various situations in education setting: face-to-face, distance learning, and blended learning. Distance learning is 
further divided into online distance learning (ODL), modular distance learning (MDL), and television and radio-based instruction (TV-RBI). Combining any of the modalities is also possible, and it is called the blended learning. The combination of ODL and face-to-face popularized what we now call as flipped classroom, wherein several studies have proved the learning modality as effective in delivering competency to learners. The combination of MDL and face-to-face give rise to what is called remote learning wherein only a portion of the allotted time is spent in the classroom, while the rest of the lesson and activities are already laid down in the module that is being distributed to the learners. Other combinations of the learning delivery modalities are being studied and prepared for large audience like combination of MDL and TV-RBI. Online distance learning, in itself, if divided into three sub-modes: synchronous, asynchronous and hybrid. Synchronous approach allows all students and their teachers to interact at the same time resembling what a physical classroom looks like. The only difference is that they are located in different places but are connected using a particular tool of communication powered by the internet. Asynchronous learning approach provides students some flexibility as they are the ones to choose when and where to take their assigned courses and lessons. Virtual teachers maximize the use of pre-recorded materials to give out instructions to their students. The common tools used in an asynchronous learning method are e-mail, digital library, discussion threads, and pre-recorded audio and video. Hybrid or blended learning basically represents the synchronous and asynchronous learning approaches. Educators may opt to combine tools from the first two methods to promote blended learning depending on the needs of their students.

Having said all the learning modality, this study focused on the concepts surrounding the modular distance learning (MDL). What are the challenges being faced by the school and stakeholders that implements modular distance learning this school year 2020-2021? What are the determining factors that would make the collaboration of parents, teachers and learners become effective in modular distance learning?

Regional Memorandum 296, series of 2020 stipulates the following:

"All parts of the original DLL/DLP are subsumed in PIVOT4A lesson exemplars. These lesson exemplars shall replace daily lesson log or daily lesson plan (DLL/DLP) during this period for teachers to manage and maximize their time, learning resource adjustment, preparations and other teaching resources. At the end of each month, teachers are enjoined to develop supplementary materials to be used by learners in each lesson cycle."

The I.D.E.A. lesson exemplar has four phases, namely, Introduction, Development, Engagement and Assimilation. Each of these phases has corresponding learning experiences that are expected to be built alongside learning. For the Development phase, the learners should be able to collaborate (see figure below) not only with the classmates but also with their teachers.

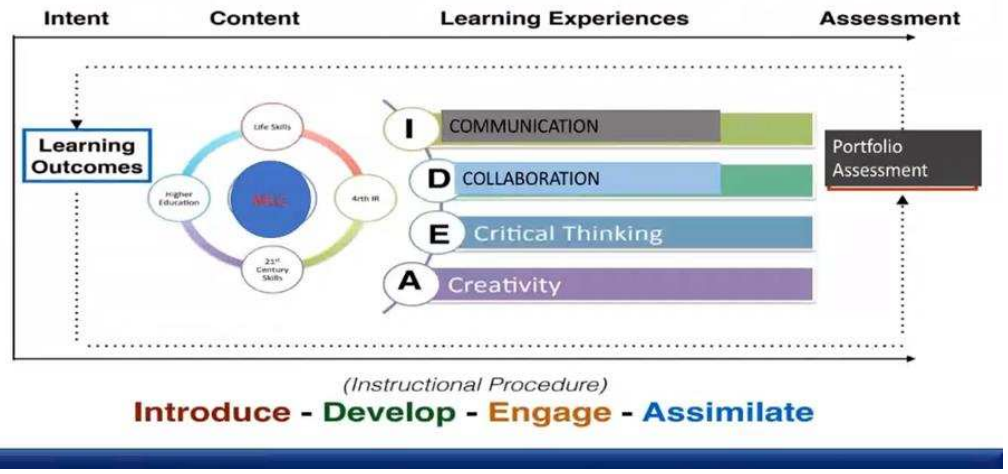

Fig. 1. Instructional Design using Multimodal Learning Delivery 
Using the modular distance learning (MDL), an additional workforce that would be needed in the collaboration is the parents. So aside from the teacher and the learners, the parents has important role to do for the learners to achieve maximum learning out of the modules being distributed to them. This may not be confined into guidance, supervision and monitoring, as this study would like to explore. How much of the part of the parents is needed in the collaboration in order for the learners not to lag behind the activities in the modules? What important role do teachers play, aside from checking learners' progress, in assuring quality education? How can strength-based learning, independence, self-motivation and good study habits be formed to young minds who will first experience having modular distance learning?

\section{Review of Related Literature}

According to the Department of Education (2019) in their book entitled "Alternative Learning System Education and Skills Training Handbook for Implementers" (2019), learning modules are "printed or non-printed materials." They are both for the teachers and the learners intended to guide them in the process of acquiring knowledge, values and competencies. They can be in text or video format. Even online distance learning makes use of a module before the synchronous, asynchronous or hybrid approach can be implemented. They all start in a production of a module.

The production of a module, though most are coming from higher authorities like the Division, Region or Central Office, should be contextualized or indigenized when brought down to the classroom setting. This is what the Department of Education D.O. 32, s. 2015 stipulate. In the said provision which is rooted in the Indigenous People Education Curriculum Framework or IPEd, schools should localize, indigenize and enhance $\mathrm{K}$ to 12 Curriculum so as to go with the social context of the community.

Hernando-Malipot (2020) shared a partial report of the enrollees for basic education (K to 12 ) in the Philippines as of July 2020. She mentioned 7.2 million learners preferring modular distance learning while only 2 million preferring online distance learning. This shows a discrepancy in choice of modality mode by 5.2 million, which is a very large difference.

Vibal (2020) in its webinar entitled "Senior High School in the New Normal: Trends in Conducting Classes and Administrative Operations" with the resource speaker Dr. Mary Erika Bolaños set the dividing line between a textbook, a syllabus, a lesson plan, and a learning module. Though the module can do all the things that the other three can do, it does it in a different and specific way. Lesson plan primarily is for teacher's use but the learning module is both for the learner and the teacher. A textbook showcases the ingname suggests, is flexible or modular in nature, in which the learner can still learn more than what the module presents through world-web lings to textual, audio, video, or other embedded media. A syllabus is concise and does not communicate well with the learner with regards to the content of the lesson, while a learning module or a packet is user-friendly, explicit in instruction and somehow complete in information. Also, a learning module elicits response, expects output, or prompts dialogue while a syllabus or course guide does not because it just gives the outlined content and topics to be covered in a given period of time.

Bro. Roderick Aguirre through Vibal (2020) webinar entitled "Using Vibal MDL Materials: A Walkthrough and Practical Reminders for Teachers and Parents" shows disagreement with the popular notion that homeschooled children lacks socialization. On the other hand, according to him, homeschooling is a good arena where the socialization of the child with the parents, considering the ample time that they would be together, is being built, practice, enhanced or refined, so that when the child goes out in the world, he knows in what manner he should behave in communicating with different people of different culture and situation.

"Offline Learning Opportunities: Implementing Modular Approach in the Current Educational System," a Vibal (2020) webinar, has the resource speaker Sir Dax Knows defined modular instruction, "an alternative instructional design that uses developed instructional materials based on the needs of the students." 
It is created through chunks of instruction that may cover a unit, a chapter, a topic or a segment of instruction, but it is usual that a module comprises a week of reading and task accomplishment. It is linked to the idea of flexible curriculum that is why it should be done with the knowledge of learners' needs, interests, strength and experience. It should be noted that even though a module is designed primarily for the teachers and the learners, it also calls for the participation of the parents, school administrator and the society at large. Objectives of the module should be set in a realistic mode so as to cater to the current situation in which the module is purposely made. Its length does not solely depend on the teaching style of the developer of the module, or on the content of the topic, but on the learners who would be dealing with the module - their learning style, their interests, their strengths, and even their weaknesses.

A basic but nonetheless important understanding of the concept of module is discussed in the webinar by Vibal (2020) entitled "Bite-sized Distance Learning through Practical Modular Approach" with the resource speaker Dr. Glendora Tui. A module is traced back to its root meaning which is sector or section, while modular is flexible or adjustable. The connected concept with these terms is self-learning. Malcolm Knowles definition of self-learning was presented in this webinar, and it is the "process by which individuals take the initiative, with or without the assistance of others, (autonomy) in diagnosing their learning needs, formulating learning goals, identifying human and material resources for learning, and evaluating learning outcomes (mastery)." This definition takes out the center of the teaching-and-learning process from the educator, to the one who would acquire the competency or skill, and that is, the learners. A module is more learner centered because it is carefully crafted to prompt learner's desire to seek for knowledge, rather than being spoon-fed. They are given the autonomy to contribute to the materials presented in a way that they are guided on what to search and what to absorb. It is going beyond the traditional schooling from just reading a manuscript to being a lifelong learner hungry of knowledge.

Sarmiento and Orale (2016) mentioned that Philippines is one of the last countries who had evolved from a ten-year curriculum program to 12-year curriculum from elementary to high school. Neighboring countries in Asia have already adopted the K to 12 curriculum even before the Philippines started last school year 2016-2017. Our own K to 12 curriculum is patterned with modification from the United States which has three-year Middle School and three-year High School

Vibal (2020) webinar entitled "Engaging (SHS) Gen Z Learners in the New Normal Classroom," with the speaker Mr. Erwin Apostol, differentiates Gen X, Gen Y and Gen Z learners. Gen X learners were those born earlier than 1980, Gen Y are those born from 1980 to 1955, while those born beyond 1995 are called Gen Z learners and graduates. Gen Z learners are not just inclined with technology and gadgets, but are also mobile in their home living and even their choice of career after graduating. They are updated and give importance newsfeeds and this characteristic requires strategy in teaching. In presenting the lesson, it is important to deal with them immediately how they will be able to use the competency or skill that they will learn or acquire from the present discussion. Also, since the Gen Z learners are global in such a way that they tend to communicate more with the world compared to Gen X and Gen Y, educators should go along with them in being global as well.

Findings of the study made by Mestry and Grobler (2020) affirms the strengthens the view that "input from the parent community was crucial in both curricular and extra-curricular program of the school." This South African educational research found out that even though there is an existing contract that parents signed about partnership in school with regards to policy making and other program, it was observed that low participation from the parents were seen especially during school activities. Consequently, it was noted that learners whose parents are less involved in school program have lower academic performance than those who are actively participating in school affairs. This research showed that both collaboration and communication played a vital role in the education of the children and in school governance.

Loughran (2008) in her article lined up the two important elements of having a good working 
partnership between the teacher and the parent. Every parent wants to know two things about the teacher: (1) that the teacher knows their child, and (2) that the teacher likes their child. With this, the parents are assured of that only the best education will be catered to their children, and this for her is where the parent-teacher collaboration and good relationship begins.

Ritchie (n.d.) in her study on the language and literacy abilities of kids with Down Syndrome found out that they tend to perform better when the environment is positive, and this is true for in school and at home. Constant communication between the teacher and the parents should be established so as to provide the kids with this kind of environment. She attested that collaboration and communication between teachers and parents is an important aspect of student learning.

Dewarle (2014) in her study focused in investigating on how teachers can support parents, and how parents can support teachers in creating meaningful and engaging literacy opportunities for a child. She found out that parents do not always wish to communicate ideas or happenings at home because the teacher may view it negatively. She motioned that teachers can support parents at home by suggesting an adjustment in a daily routine of a child at home which can foster child's literacy development. Also, she suggested at the end of the study that schools should empower the parents at home in meeting the needs of a child through family literacy initiative that naturally occur at home.

The idea of teacher-parent communication and collaboration seem to permeate only to inclusive education at present. It was seen in the discussion of literature that it is confined to students with Down Syndrom or in special education. Such is the study made by Adama, Harris and Jones (2016) which focused on inclusive education and the partnership of teachers and parents. The main problem that they have encountered in having a meaningful collaboration is the difference in the ideas and beliefs between the school and home. The collaboration between the teacher and the parents create more inclusive classroom environment because the parents show support and the teachers get idea from the parents as to how to best possibly deal with the children. With both the teacher and the parents having accountability with the progress of the learners, the teaching-and-learning process becomes smooth and more enjoyable. The suggestion of the authors in this study is the existence of fluid partnership that would avoid possible emergence of tension affecting child's educational experience.

Santana (2014) explored on the power of conducting a workshop to parents, handled by teachers. Through the workshop, positive learning environment and mutual respect were formed, leading to parentteacher collaboration which begins with creating common areas of interest to explore. When this communication became constant, the benefits were clearly seen through learners' academic growth and increased interest of parents in the learning experiences of their children.

The existing issue that Griffin (2014) tackled in the beginning of the study is that parents believe that their participation is not needed, though there is already an existing Individualize Education Program (IEP) in the school. Through the study, the issue was attested because parents expressed that they do not perceive a fully open communication and a transparent collaboration. Though school made an effort to generate comfortable environment for a holistic collaboration through formal meetings, the parents still felt frustration in the special education process including the initiation of services. It was recommended at the end of the study that policy makers should be more involved in the setup of classroom level so as to make innovations on policy and governance.

All the above-mentioned readings and previous studies would shed light in the interpretation and analysis of the developed ideas from the responses of the participants, and would gear towards producing meaningful themes. 


\section{Research Design and Methodology}

\subsection{Population/Respondents}

The participants in this study constituted of the teachers, parents and learners of General Academic Strand (GAS), Accountancy, Business and Management (ABM) and Caregiving tracks of Talangan Integrated National High School, school year 2020-2021. The table below shows the frequency of the respondents for this study.

\begin{tabular}{|c|c|}
\hline Respondents & Frequency \\
\hline Teachers & 4 \\
\hline Parents & 6 \\
\hline GAS Learners & 2 \\
\hline ABM Learners & 2 \\
\hline Caregiving Learner & 1 \\
\hline Total & $\mathbf{1 5}$ \\
\hline
\end{tabular}

3.2 Data Gathering Procedure

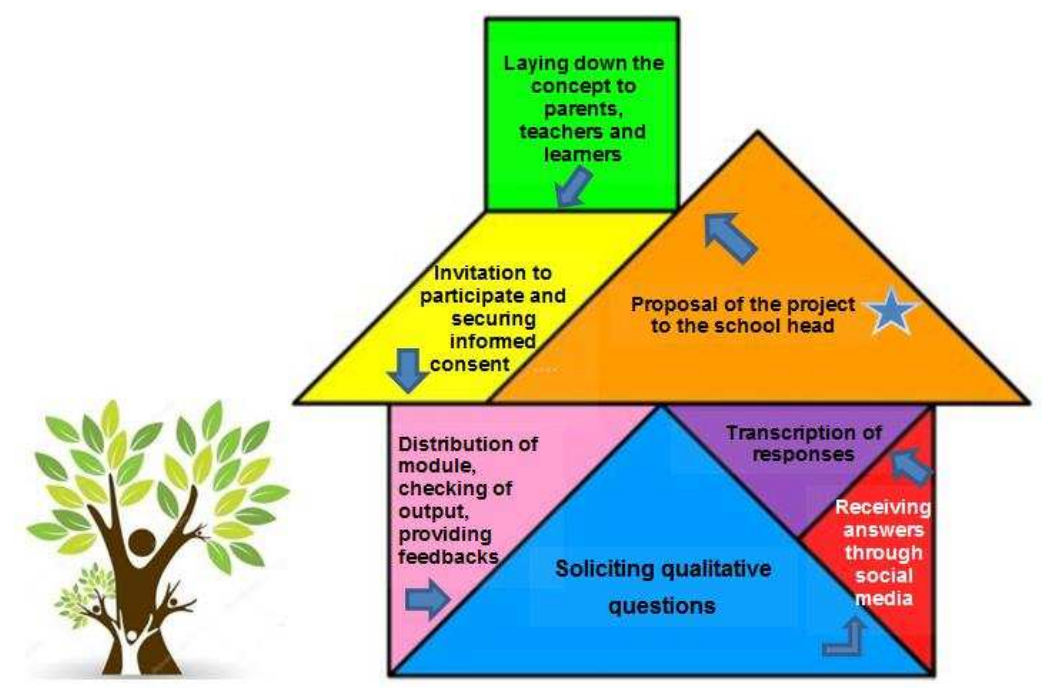

Fig. 1. Flowchart of Data Gathering Procedure

The figure shows the step-by-step procedure executed in gathering data for this study. The author communicated the idea to the school principal of the subject school, Talangan Integrated National High School. The project was then disseminated to the parents, teachers and learners through the guidance office webinar initiative because the school year 2020-2021 started. Parents, teachers and learners were invited to participate and those who willingly responded were noted for informed consent. The start of the school year signaled the start of modular materials distribution as well. As the schooling of the learners progressed, qualitative questions were solicited to parents, teachers and learners every week, focusing on their experience on modular distance learning. Responses were received through social media, particularly the messenger app of Facebook. Responses were transcribed, ready for thematic analysis and interpretation. 


\subsection{Data Gathering Instrument}

The author of this study gathered data for this study through qualitative questions that focused on modular distance learning. Four questions were provided to investigate on parents' role in collaboration, four questions for teachers' role in collaboration, and two questions for learners' part in collaboration. The respondents were asked to provide at least three complete sentences in answering the questions. Responses were harvested from Google forms. Whenever needed, the researcher contacted the respondents to clarify things that may be obscured from their response, or things that may add light to the topic. Follow up questions were done through Facebook messenger or through mobile phone call. These additional responses were also put into transcription for Word cloud analysis.

\section{Results and Discussion}

\subsection{Parents Supervising Learners despite Working}

The first qualitative question given to the participants was this: "In what ways can parent supervise or guide their children in dealing with modular lessons, even if they have other works to do?"

Seven words/phrase frequently appear in the responses of the 15 participants: "inquire", "relatives", "communication", "elders", "assistance", "family members" and "progress". Their responses were summarized into four ideas:

- Parents can spend quality time during night time to inquire of the progress of their child based on the subject loads given by the school.

- Other family members can be given a task assist the learners while dealing with modular tasks.

They can be the elders in the house, siblings, or other relatives who may be residing nearby.

- If parents stay at home, they can secure the learners place of study, provide assistance from time to time, prepare meals, and serve as referee from distractions like peers, mobile games and other unnecessary hobbies.

- If they work outside home, they can inquire of the learners' progress through phone call, text message, or other means of communication to the learner or to the people supervising the learner at home.

Findings of the study made by Mestry and Grobler (2020) showed that both collaboration and communication between the school and parents played a vital role in the education of the children and in school governance. This deepens the claim that parents guidance to children at home is indispensable for the learners' success in modular distance learning.

Based from the frequently appearing words, the summary of participants' responses, and the external analysis, the first theme developed is this:

"Earning for a living is not a hindrance to supervising children in MDL."

\subsection{Parents' Profile that Assist Learners in Becoming Independent}

The second qualitative question given to the participants was this: "What are the parents' characteristics that would lead children become motivated and independent in accomplishing their modular tasks?

Seven words frequently appear in the responses of the 15 participants: "discrete", "patient", "weaknesses", "optimistic", "influence", "loving" and "caring". Their responses were summarized into four ideas: 
- Parents should be discreet with regards to the schedule that learners should follow in dealing with the modules.

- Parents should be patient with their child's weaknesses and shortcomings.

- Parents should maintain an optimistic attitude because this influences the learners demeanor in dealing with his different subjects at home.

- Parents should be loving and caring, enough for the learner to know that he is given attention, not necessarily constant assistance, in answering the modules.

According to Roderick Aguirre in Vibal (2020), homeschooling is a good arena where the socialization of the child with the parents is being built, practice, enhanced or refined, so that when the child goes out in the world, he knows in what manner he should behave in communicating with different people of different culture and situation. Independence is built primarily at home in the context of this type of learning delivery. This is in consonance with the present study although it deals in modular distance learning and not homeschooling.

Based from the frequently appearing words, summary of participants' responses, and the external analysis, the second theme developed is this:

"Learners develop independence in studying through parents' discreet guidance and affection."

\subsection{Parents' Hindrances in Collaboration}

The third qualitative question given to the participants was this: "What are some of the hindrances for parents to collaborate in the teaching-and-learning process?"

Seven words frequently appear in the responses of the 15 participants: "confidence", "direction", "time", "guidance", "working", "school" and "teacher". Their responses were summarized into four ideas:

- Lack of confidence in doing their important task in the collaboration

- Lack of time because they are also working

- No clear direction from the school

- No explicit guidance from the teacher.

It can be said, based on the four major ideas presented by the participants that there are internal and external factors that hinder effective collaboration of parents with the school. Internal factors are those developed by the parents within themselves, therefore, the parents are held accountable with those things, like lack of confidence and having time mismanagement between parental guidance and work. On the other hand, external factors are those which are beyond the accountability of the parents, like having no or little direction from school and no explicit guidance from the teacher/adviser. Consequently, both of these factors can be mitigated through interventions initiated by schools. Even if there is a contract that parents sign at the beginning of the school year, it is important that the intervention is continuous. This is what Mestry and Grobler (2020) found out in their study. Low participation from the parents were observed during school activities if the intervention is just in the beginning of the school year. Programs for parent-school collaboration should be sustained throughout the school year.

Based from the frequently appearing words, summary of participants' responses, and the external analysis, the third theme developed is this:

"Parents' hindrances to collaboration can be classified as internal and external in which, both can be mitigated through school intervention."

\subsection{Parents' Assistance in Modular Distance Learning}

The fourth qualitative question given to the participants was this: "How should parents deal with 
assisting their child in modular tasks when the scope of the lesson is beyond their experience or knowledge?"

Seven words frequently appear in the responses of the 15 participants: "read", "teacher", "clarification", "assistance", "family", "search" and "internet". Their responses were summarized into four ideas:

- The parent can call the teacher for some clarification.

- The parent can ask assistance from the older siblings, or other member of the family.

- The parent can make a search on the internet with regards to a different topic.

- If parents have time, they can also read or browse the module and provide assistance to the learner if they are able to understand the material.

The ideas above once again strengthen the claim of Bro. Roderick Aguirre through Vibal (2020) webinar entitled "Using Vibal MDL Materials: A Walkthrough and Practical Reminders for Teachers and Parents" that parents' input is beneficial even if they are working for a living. Nothing can be compared to the assistance that a parent can give in order for the learner to succeed in distance learning. If the parent's knowledge is beyond the scope and competencies of this generation, there are many things that the parent can explore in order to provide assistance to learners. There is the social media, the world wide web, the subject teachers' assistance, and even the family members who are staying at home with the learner - older siblings, relatives, and elders.

Based from the frequently appearing words, summary of participants' responses, and the external analysis, the fourth theme developed is this:

"Parents' assistance to learners in MDL can include personal guidance, family intervention, communication to teacher and web browsing."

\subsection{Teachers' Preparation of Module and Supplemental Materials}

The fifth qualitative question given to the participants was this: "How modules and supplemental activities should be prepared for learner's utilization?"

Seven words frequently appear in the responses of the 15 participants: "learner", "interest", "knowledge", "preference", "best", "future" and "suit". Their responses were summarized into four ideas:

- In preparing supplemental activities, teachers should consider the learners' interest.

- In preparing supplemental materials, teachers should have knowledge of how the learners learn best.

- Supplemental activities should suit the learners' learning preference.

- Future content that can be previewed should be in mind in preparing supplemental activities.

The ideas presented by the respondents are in consonance with what Vibal (2020) webinar pronounces through their speaker Sir Dax Knows. The said webinar emphasizes that the materials, both module and supplemental activity, should be based on the needs of the students, and not just on the competencies provided by the education department. The first three of the general ideas obtained from the respondents can be summarized into the following notion: learners' interest, learner's style, and leaners' preference. These jive with the concept of learner's needs, and this calls for having the profile of the learners in-tack with the school and the adviser. The last of the four ideas mentioned above deals with the connection of the topic to the other competencies, making a scaffolding of learning that speaks of a constructivist approach.

Based from the frequently appearing words, summary of participants' responses, and the external analysis, the fifth theme developed is this:

"Module and supplemental materials, while aiding for scaffolding of learning, should be aligned with students' needs, interest and learning style." 
4.6 Benefits of Using Supplemental Materials

The sixth qualitative question given to the participants was this: "What are the benefits of supplemental activities to the modules distributed to learners?"

Seven words frequently appear in the responses of the 15 participants: "additional", "information", "assistance", "objective", "differences", “enhance" and "skills". Their responses were summarized into four ideas:

- They provide students who want to know more about the topic additional information.

- They provide assistance to learners in meeting a particular objective.

- They support learners' differences.

- Enhance skills of learners especially in subjects that require computation and other routine skill.

As individual difference became popular in the late 1980's, thus giving birth to multiple intelligences, so the $21^{\text {st }}$ century or Gen $\mathrm{Z}$ learners are more complex in terms of their variety of interest and range of inclinations. Mr. Erwin Apostol through Vibal (2020) webinar mentioned that Gen Z learners are updated to newsfeed, requiring variety of strategy and material in order to catch their wide-range of topicinterest. They also tend to communicate with the world, thereby requiring materials that deal with world issues or context. This is the reason why learner-, teacher- and parent-participants of this study viewed supplemental materials benefits as provider of additional information, assistive of achieving learning objective, solution to individual differences, and avenue for enhancement of wide-range of skills.

Based from the frequently appearing words, summary of participants' responses, and the external analysis, the sixth theme developed is this:

"Supplemental materials are beneficial in meeting the learning characteristics of $21^{\text {st }}$ century learners and an aid in achieving learning objectives."

\subsection{Teachers' Encouragement for Parents to Collaborate}

The seventh qualitative question given to the participants was this: "How can teachers encourage parents in the collaboration process?"

Seven words frequently appear in the responses of the 15 participants: "interview", "info graphics", "webinars", "listen", "show", “objectives" and "communication". Their responses were summarized into five ideas:

- Set a schedule for public interview with the parents.

- Provide info graphics, video or webinars that contain information on how teachers can assist parents at home.

- Listen to the responses or feedbacks of the parents regarding the school, the teachers, or the module.

- Show the complete list of learning objectives or competences at the start of the school year to every parent and learner.

- Be open in communication and in providing feedbacks to learners and parents.

The study made by Mestry and Grobler (2020) shows an intriguing scenario in most schools. Even if the guidance office initiates a rigid program so that the school can win parents' support, the attendance of parents in school activities dwindles as months pass. The energy of the parents seemed to be not sustained as after the opening of classes. This can be due to the reason that it is the mainly the teachers or the advisers who are encouraging the parents to support the school. The five ideas developed from the responses of the participants imply that the teachers should to the initial action because they are the ones who are first in line in terms of parents' contact to school. Teachers interview to parents show real concern for the learners' 
development, thereby giving an indication that in school, the learner is being taken cared of conscientiously, and not just a way to earn money. Providing info graphics, webinars, pliers, brochures or videos about the school's events lead to parents having interest to join, support the project, or be acquainted with school curriculum. Opening up the communication takes away the barrier and the notion that parents are being put in hot seat whenever there are shortcomings from the learners, thus, creating meaningful collaboration for the learners' progress.

Based from the frequently appearing words, summary of participants' responses, and the external analysis, the seventh theme developed is this:

"Teachers can motivate parents in the process of collaboration when they reach out, give quality time and show real concern for learners' interest."

\subsection{Teachers' Feedbacks for Learners' Progress}

The eighth qualitative question given to the participants was this: "In what ways are the teachers' feedbacks to learners' progress in a module lesson help the learners to proceed with their academic status?"

Seven words frequently appear in the responses of the 15 participants: "motivate", "right", "corrective", "target", "ensure", "accomplishment" and "parents". Their responses were summarized into four ideas:

- Feedbacks motivate the learners by knowing that he is at the right track.

- Feedbacks provide corrective measure when the learners miss the target of what he is supposed to acquire.

- Feedbacks ensure the learners of the teachers' attention to his works and accomplishment.

- Feedbacks also guide the parents to further assistance that he can give to the child.

The issue of collaboration is again seen in the aspect of feedback giving a sign for parents on what assistance is needed to guide the learner towards producing a better output. The study of Dewarle (2014) showed how the teachers and the parents can collaborate on this aspect. The parents, upon seeing the feedback of the teacher to his/her child with regards to non-attainment of the needed competency, can make adjustment on the schedule of the child in doing task at home, or can give an aid on proper time management. This is just one of the many benefits of having teachers' feedback. Different from the learners' academic performance, feedbacks give direction on how the learner can improve his work. Feedback encourages, motivates, enlightens, and gives a picture of how the learner is going through the right path of learning. Through teachers' feedbacks, learners are able to communicate with the teacher, ensuring a good relationship, and thus, motivates the learner because he knows that he is being guided.

Based from the frequently appearing words, summary of participants' responses, and the external analysis, the eighth theme developed is this:

"Teacher feedbacks are important element of collaboration because learners are motivated through corrective measures and parents are informed if close supervision is needed."

\subsection{Learners' Reception of Parents' and Teachers' Assistance}

The ninth qualitative question given to the participants was this: "How should learners welcome or expect the assistance of parents and teachers in leading them towards success in modular distance learning?"

Seven words frequently appear in the responses of the 15 participants: "follow", "approach", "difficulty", "encouraged", "feedbacks", "supportive" and "success". Their responses were summarized into four ideas:

- Learners should willingly follow the schedule given by the school. 
- Learners should approach or contact parents, whenever possible, if he finds difficulty, knowing that parents are the first teachers and home is the first school.

- Learners should be encouraged with corrective feedbacks with his shortcomings and accomplishments.

- Learners should heed the parents' and teachers' supportive discipline if he wants to be guided towards success.

For the learner to succeed in modular distance learning, he must clearly see the wonderful collaboration of the parent and teacher. For the parents to collaborate with the teacher, they are looking for two things: that the teacher knows their child, and that the teacher likes their child (Loughran, 2008). If these two things are in place, then the partnership is developed. On this note, the learner can easily embrace any assistance coming from his parents and teachers. Whatever discipline, rules or regulation that can help him should be positively welcomed, even if sometimes it would cause him some changes in his behavior, routine or choices. He should feel free to approach any of the two, or both of them, for assistance in areas he finds difficulty with. Instead of having a feeling of resentment when feedbacks show his shortcomings, he should looked at it as encouragement, a support for him in order to have success in the future.

Based from the frequently appearing words, summary of participants' responses, and the external analysis, the ninth theme developed is this:

"Learners should have an open mind in the feedbacks and assistance of parents and teachers because this will lead for them success in $M D L . "$

\subsection{Effective Learning Habits in Modular Distance Learning}

The tenth qualitative question given to the participants was this: "What are the effective learning habits that students need to bear in mind in dealing with modular distance learning?"

Seven words frequently appear in the responses of the 15 participants: "cramming", "goal", "procrastinating", "challenging", "distractions", "groups" and "review". Their responses were summarized into seven ideas:

- Avoid cramming all study sessions in just one sitting.

- Have a specific goal for each study session.

- Avoid procrastinating in the scheduled study time.

- Begin exploring the subject that is most challenging for the learner.

- Avoid distractions while studying.

- Join study groups.

- Review lessons during weekends.

Three words that seem to be negative in connotation are cramming, procrastinating and distractions. That is why these should be avoided in the context of modular distance learning. Dr. Glendora Tui in the webinar by Vibal (2020) emphasized that modules should be learner centered, and therefore should cause learners to be independent seeker of knowledge and not just being spoon-fed. Learners need to go beyond the traditional teaching of just reading and having remote learning, to being hungry of knowledge and seeking it beyond the materials provided to them. Learners need to have a goal whenever he receives materials from the school. He can join study groups in social media where he can interact and learn things in a different way as they were presented in the materials. And at end of each week, they need to recall or review concepts that they have encountered so as to strengthen learning.

Based from the frequently appearing words, summary of participants' responses, and the external analysis, the tenth theme developed is this:

"Learners should avoid cramming, procrastinating and distractions, and clearly set goals for themselves 
associated with every modular lesson.”

\section{Recommendations}

The following are suggested actions based on the themes developed in this exploration.

- Parents should relive the concept of being the first teachers at home. Lessons are first taught at home and it is still true in this time of pandemic.

- Teachers are encouraged to be vibrant in the delivery of competency through careful attention in the production of module and/or supplemental materials. Their important role as encourager to parents is also indispensable as many parents would like to collaborate and they just don't know where to begin and how to best cooperate.

- Learners should willingly welcome assistance from others as this time of pandemic really entails the need for several outlets mentally, psychologically, morally and spiritually. Developing good study habit would secure for them real learning and not just having the modules and materials for the sake of reading, writing and passing.

-. School officials should institutionalize collaboration so that when this pandemic is over, the culture of joining together hand-in-hand would still continue for continuous progress of education. Collaboration should not be a one-time project or program but system that needs to be embraced whatever the mode of learning is being implemented.

- Future researchers should explore on the deeper aspect of collaboration in other modes of learning like online and blended. The television and radio instruction-based instruction (TVI) is also a mode of learning that needs parents' guidance as kids watch the show or hear the broadcast. The comparison or contrast of collaboration can be investigated as schools may shift from one learning modality to another in the next school years to come.

\section{Acknowledgment}

The author wishes to acknowledge the 15 participants who have largely contributed in the production of this study. They are composed of 6 parents, 4 teachers and 5 learners. During the course of modular distance learning, while they were busy in their own tasks, they willingly offered their precious time answering the interview questions and sharing their ideas as they were currently experiencing collaboration in modular distance learning. The author's utmost gratitude is being relinquished to them as they represent the lead roles in modular distance learning collaboration - the PARENTS, the TEACHERS and the LEARNERS.

\section{References}

Adams, Donnie, Alma Harris and Michelle Jones. (2016). "Teacher-Parent Collaboration for an Inclusive Classroom Success for Every Child.” Malaysian Online Journal of Educational Sciences, Volume 4, Issue 3

Creswell, John W. (2003). Research Design: Qualitative, Quantitative, and Mixed Approaches (2 $2^{\text {nd }} \quad$ ed.). Thousand Oaks, CA: Sage.

Department of Education. (2019). Alternative Learning System Education and Skills Training Handbook for Implementer. Meralco Avenue, Pasig City 1600, Philippines

Department of Education. DepEd Order 32, s. 2015. Adopting the Indigenous Peoples Education

Department of Education. Regional Memorandum 296, series of 2020.

Dewarle, Jessica. (2014). Parent-Teacher Collaboration: Sharing Knowledge to Support a Child's Literacy Development. A 
project submitted in partial fulfilment of the requirements for the degree of Master of Education in Special Education. Vancouver Island University, Nanaimo, British Columbia, July 2014

Griffin, Heather R. (2014). The Importance of Collaboration Between Parents and School in Special Education: Perceptions From the Field. A dissertation submitted to the Doctoral Faculty of the College of Education and Human Services in partial fulfilment of the requirements for the degree of Doctor of Education Educational Leadership. University of North Florida College of Education and Human Services.

Hernando-Malipot, Merlina. (2020). "DepEd: Most students prefer 'modular' learning over online.” Manila Bulletin, July 3 , 2020. https://mb.com.ph/2020/07/03/deped-most-students- prefer-modular- learning-over-online/

Loughran, Sandra B. (2008). The Importance of Teacher/Parent Partnerships: Preparing Pre-Service and In-Service Teachers. "Journal of College Teaching \& Learning," August 2008 Volume 5, Number 8 35. Dowling College, USA.

Mestry, Raj, and Bernardus Grobler. (2020). Collaboration and Communication as Effective Strategies for Parent Involvement in Public Schools. University of Johannesburg Retrieved August 27, 2020. https://www.researchgate.net/publication/228971318_

Collaboration_and_communication_as_effective_strategies_for_parent_involvement_in_public_schools.

Ritchie, Emily. (n.d). Effective Collaboration between Teachers and Parents: Discovering how to unlock Literacy and Language Abilities in students with Down Syndrome. A research paper submitted in conformity with the requirements for the degree of Master of Teaching Department of Curriculum, Teaching and Learning Ontario Institute for Studies in Education of the University of Toronto

Santana, Marisela. (2014). Parents and Teachers Working Together to Enhance Student Success in the Classroom. California State University, Monterey Bay.

Sarmiento, Danilo, and Ronald Orale. (2016). Senior High School Curriculum in the Philippines, USA, and Japan. Journal of Academic Research. 1. 12-23. https://www.researchgate. net/publication/318494693_Senior_High_School_Curriculum_in_the_ Philippines_USA_and_Japan

Todd, Michael. (2018). John Creswell on the Value of Qualitative Approach. "Social Science Space”, June 15, 2018 